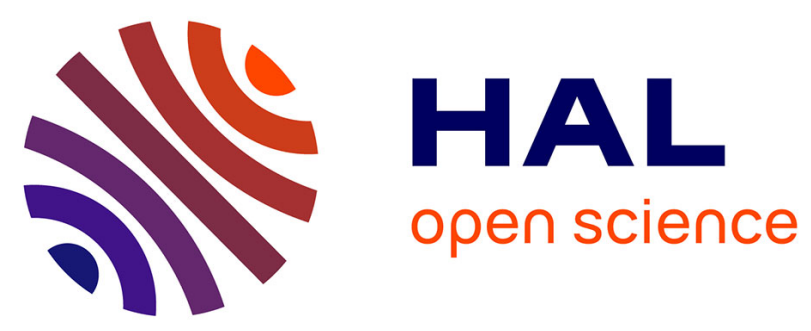

\title{
Adult neurogenesis promotes balance recovery after vestibular loss
}

Brahim Tighilet, Christian Chabbert

\section{To cite this version:}

Brahim Tighilet, Christian Chabbert. Adult neurogenesis promotes balance recovery after vestibular loss. Progress in Neurobiology, 2019, 174, pp.28-35. 10.1016/j.pneurobio.2019.01.001 . hal-02392744

\section{HAL Id: hal-02392744 \\ https://hal.science/hal-02392744}

Submitted on 21 Oct 2021

HAL is a multi-disciplinary open access archive for the deposit and dissemination of scientific research documents, whether they are published or not. The documents may come from teaching and research institutions in France or abroad, or from public or private research centers.
L'archive ouverte pluridisciplinaire HAL, est destinée au dépôt et à la diffusion de documents scientifiques de niveau recherche, publiés ou non, émanant des établissements d'enseignement et de recherche français ou étrangers, des laboratoires publics ou privés.

\section{다)(1) $(5$}

Distributed under a Creative Commons Attribution - NonCommercial| 4.0 International 


\section{Adult neurogenesis promotes balance}

\section{recovery after vestibular loss}

Brahim Tighilet and Christian Chabbert

Aix Marseille Université-CNRS, Laboratoire de Neurosciences Sensorielles et Cognitives, LNSC UMR 7260. Equipe Physiopathologie et Thérapie des Désordres Vestibulaires, Marseille, France.

\section{One-sentence summary:}

Unexpected reparative role of adult neurogenesis

\section{Correspondence to:}

Brahim Tighilet, Aix Marseille Université-CNRS, Laboratoire de Neurosciences Sensorielles et Cognitives, LNSC UMR 7260. Equipe Physiopathologie et Thérapie des Désordres Vestibulaires, 3 Place Victor Hugo, 13331 Marseille Cedex 3, France

Phone: +33 413550881; Email: brahim.tighilet@univ-amu.fr

\section{Conflict of interest:}

The authors declare no competing financial interests. 


\begin{abstract}
:
A phenomenon called vestibular compensation occurs after peripheral vestibular loss. This process involves a mosaic of profound structural rearrangements within the vestibular nuclei. Among them, adult reactive neurogenesis is perhaps the most unexpected, as it occurs in a brain area that was never reported as neurogenic before. Both the survival and functionality of this newly generated neuronal network depend on its integration into preexisting networks in the deafferented structure. Far from being aberrant, this organization allows the brain to use inputs from other sensory modalities to facilitate the restoration of posture and equilibrium. This is the best example so far of the reparative role of adult neurogenesis. Recent findings show that a similar phenomenon exists in other brain sensory structures, such as auditory brain stem nuclei and sensory motor cortex. This raises questions about the putative functional relevance of the reactive neurogenesis.
\end{abstract}

\title{
Introduction
}

The purpose of this review is not to provide an umpteenth material about adult neurogenesis, as this subject has been extensively documented in the literature. Rather, it sets out to highlight a unique phenomenon that occurs in a brain area which does not belong to the traditional niches of adult neurogenesis. Here we describe the permissive environment that allows vestibular neurogenesis to occur and points out on the regulatory cellular and molecular mechanisms involved. We also provide evidence of the functional benefit of vestibular neurogenesis in postural and equilibrium recovery. We finally address the various issues that this phenomenon raises and open up perspectives on the potential use of this phenomenon in the clinical field, as this process might be shared by other sensory modalities.

\section{The vestibular system: a finely tuned functional architecture}

The vestibular nuclei (VN) of the brainstem constitute a peculiar area of the brain in many respects. First, they act as a "hub", receiving heteromodal sensory information related to body position. Angular and linear head accelerations (including Earth gravity) are detected by specific sensors located in the inner ear and conveyed to the central VN through the $8^{\text {th }}$ cranial nerve. The VN also collect proprioceptive, tactile and visual inputs. Their main role is to integrate this plethora of sensory information and to convert the sensory information into 
motor information. Indeed, VN neurons project onto oculomotor and trunk muscles and to the upper and lower limbs, allowing us to stabilize our gaze and control our posture both at rest and during motion via the vestibulo-ocular, vestibulo-cervical, and vestibulo-spinal reflexes. These nuclei have the particularity of being both sensory and motor (Angelaki and Cullen, 2008). The information the VN process also contributes to perceptual or cognitive functions, such as the appreciation of body verticality and the body's orientation in space (Lopez, 2016). Another particularity of the $\mathrm{VN}$ is that they modulate vestibular sensory information through a direct tuning action on the sensitivity of peripheral vestibular sensors via the efferent fiber pathway (Brichta and Goldberg, 2000). Finally, the interconnection of the VN with neurovegetative structures supports the discomfort felt in vestibular disorders (Balaban, 1999) (Fig. 1A).

Vestibular syndrome: a set of oculomotor, postural, perceptual, cognitive and vegetative disorders

When vestibular sensory inputs are suddenly altered, an acute vestibular syndrome arises that includes postural imbalance at rest and during movement, spontaneous eye beats (nystagmus) and oscillopsia, which are associated with cognitive and neurovegetative disorders. These disorders occur through alterations of the vestibulo-spinal and vestibulo-oculomotor reflexes, as well as through the modification of the vestibulo-cortical signals (Angelaki and Cullen 2008; Jones et al., 2009; Lacour and Tighilet, 2010). Patients experience acute vestibular syndrome in cases of unilateral peripheral vestibulopathy, such as that encountered in vestibular neuritis, Ménière's disease or labyrinthine fistula (Strupp and Arbusow, 2001). Symptoms progressively decline, each with its own kinetics, generally leading to an almost full disappearance of the syndrome. This behavioral recovery phenomenon is referred to as "vestibular compensation" (Lacour et al., 2016) (Fig. 1B). In most species, the postlesional vestibular syndrome includes both static deficits (those present in absence of body movement) and dynamic deficits (present when body is moving). Static deficits include oculo-motor (spontaneous nystagmus) and postural (head tilt and postural unsteadiness) alterations that are compensated within a few days or weeks, while dynamic deficits (vestibulo-ocular and vestibulo-spinal reflexes and locomotor performance) are compensated much less completely over a longer time period (reviewed in Dieringer, 1995; Darlington and Smith, 2000).

\section{Reactive molecular and biochemical rearrangements in the deafferented vestibular nuclei}


Animal models of vestibular loss have revealed that acute vestibular syndrome originates from electrophysiological asymmetry between intact and deafferented VN and that recovery from this syndrome occurs through a rebalancing of this electrical activity (Smith and Curthoys, 1989, Darlington et al., 2002). The return to electrophysiological homeostasis, considered the key parameter for vestibular functional recovery, takes place via a mosaic of biological events occurring specifically within the deafferented VN. Some of the changes are restricted to an acute phase lasting from hours to several days, while other are maintained over a chronic period lasting several months (Fig. 2). The time course of the cellular and molecular events that support this process is now well documented (Lacour and BernardDemanze, 2015). In a first acute phase, upregulation of immediate early genes (IEGs) occurs over the very early hours and days, with Fos immunoreactivity peaking at $2 \mathrm{~h}$ postlesion and Zif-268-immunoreactive neurons peaking at 1-3 days postlesion. The expressions of both of these IEGs decreased progressively within 3 days to 1 week (Gustave Dit Duflo et al., 1999; Lacour and Tighilet, 2010). Many plastic events are increased and peak at 3 days. Neurotrophin immunoreactivity occurs one day after lesionning, with peak expression of the brain-derived neurotrophic factor (BDNF) observed at 3 days in the $\mathrm{VN}$ and related structures, and a return toward basal expression within the first week after lesioning. A similar spatiotemporal pattern has been observed for the nerve growth factor (NGF), neurotrophin 3 (NT3), and their respective TrKA/TrKC receptors (Lacour and Tighilet, 2010). These changes in turn regulate different neurotransmitter systems, such as gamma-aminobutyric acid (GABA), acetyl choline, histamine and noradrenaline, starting at one day after unilateral vestibular neurectomy (UVN). In parallel, excitability markers such as the cation-chloride cotransporter (KCC2), GABAa receptors and calcium-activated small conductance $\mathrm{K}^{+}(\mathrm{SK})$ channels are drastically reconfigured in this early time window (Dutheil et al., 2016, Tighilet et al., 2018). Astrocytic and microglial reactions, as well as an increase in tumor necrosis factor alpha (TNF $\alpha)$ expression are also observed at the same time (Liberge et al., 2010; Lacour and Tighilet 2010, Dutheil et al., 2011, 2016). Finally, the neurohormonal system and more specifically the hypothalamo-pituitary-adrenal axis (HPA or stress axis), is also activated. The activation of this pathways is characterized by an increased immunostaining for corticotrophin-releasing factor (CRF) and arginine vasopressin in the paraventricular nucleus of the hypothalamus as early as one day alter lesioning (Tighilet et al., 2009). A temporal correlation between the expression of the proteins involved in these acute plastic mechanisms and the reduction in the static deficits has been observed. In a second, more chronic phase, part of the modulations that started during the acute period is maintained, 
including the glial reaction, changes affecting GABAergic, cholinergic, histaminergic and noradrenergic systems, and neuroendocrine changes. Structural changes, such as reactive synaptogenesis or collateral axonal sprouting, also occur within the deafferented VN (Li et al., 2002; Raymond et al., 1991). All of the plastic events occurring during the first month postlesion indicate a critical period, which should benefit vestibular rehabilitation and during which vestibular plasticity is likely shaped by vestibular rehabilitation therapies.

\section{Adult reactive neurogenesis: an unexpected rescue mechanism}

Unexpectedly, we used histological approaches and were the first group to report the exclusive and robust induction of reactive neurogenesis in the deafferented VN (Tighilet et al., 2007). Using BrdU strong cell proliferation began one day after lesioning and peaked at three days post-UVN in the adult deafferented VN (Fig. 3A). An immediate infusion of the antimitotic drug cytosine-beta-D-arabino-furanoside (AraC) blocked cell proliferation and decreased the number of GFAP-immunoreactive cells and GABAergic neurons observed in the vestibular nuclei of neurectomized cats. At the behavioral level, after UVN and immediate AraC infusion, the time course of the recovery of postural and locomotor functions was drastically delayed, and no alterations in the horizontal spontaneous nystagmus were observed. In contrast, an infusion of AraC beginning 3 weeks after UVN had no influence on the time course of the behavioral recovery, or the proliferation and differentiation of reactive cells. We concluded that the first 3 weeks after UVN represent a possible critical period in which important neuroplasticity mechanisms occur to promote the recovery of vestibular function. During this time period, reactive neurogenesis and astrogenesis might contribute highly to vestibular compensation in the adult cat (Dutheil et al., 2009; Fig. 3B).

Many questions remain regarding the establishment and relevance of reactive vestibular neurogenesis. First, how does a mature brain environment, not known as a neurogenic site, comes to harbor new neurons. One possibility is that these newly generated neurons migrate from established neurogenic niches, such as the subgranular zone of the dentate gyrus of the hippocampus or the subventricular zone of the lateral ventricles (Gage, 2002), via the blood or the cerebrospinal fluid (Stellos et al., 2010) and then integrate into the VN on the edge of the fourth ventricle. An alternative option is that, under normal conditions, the VN constitute a neurogenic niche that hosts quiescent neural progenitors. This hypothesis is supported by the presence of cells that are immunoreactive for both SYR (sex determining region Y)-box 2 (SOX2) and (glial fibrillary acidic protein) GFAP, which are considered neural stem cell 
markers (Ferensztajn-Rochowiak et al., 2018), in the intact VN of adult mammals (unpublished data).

The second question relates to the conditions that induce stem cells migration from neurogenic areas, or factors that induce these cells to enter the cell division cycle from the quiescent state. Neurogenesis only occurs after VN structural deafferentation (eighth nerve section) rather than functional deafferentation (labyrinthectomy or pharmacological blockade) (Dutheil et al., 2011). Thus, Wallerian degeneration of the sectioned nerve fibers and the subsequent biochemical cascades may trigger the ability to produce new neurons by attracting stem cells or by removing the environmental locks that prevent neurogenesis. The fate of these undifferentiated newborn cells, how they mature and differentiate, and how they fit into a preexisting neural network and impact posture and balance recovery remain unknown. Confocal imaging and stereological analysis in a UVN cat model have indicated that among these newborn cells, $70 \%$ survive beyond 2 months. Of those cells, $40 \%$ differentiate into neurons, $40 \%$ into astrocytes, and the remaining $20 \%$ into microglial cells (Fig. 4). We do not know yet what conditions the distribution in each cell lineage. However, one can speculate that the cells with a neuronal fate will somehow integrate into preexisting functional vestibular networks. This hypothesis is strongly supported by the high proportion of new born neurons and by the mature morphology of these neurons, such as the development of dendritic arborization in one-month post-UVN new neurons (Dutheil et al., 2016). Both histological and electrophysiological approaches should confirm this hypothesis.

Why does the pharmacological blockade of neurogenesis principally impact the postural and locomotor functions, but not the nystagmus compensation? Although cell proliferation occurs in all deafferented vestibular nuclei, neuron differentiation (neurogenesis) only occurs in the medial, lateral and inferior vestibular nuclei, which are mainly associated with static and dynamic postural functions (Wilson and Melvill Jones, 1979). Thus, the specific blockade of NG exclusively impairs postlocomotor restoration (Dutheil et al., 2009). The superior vestibular nucleus is exclusively dedicated to gaze stabilization and oculomotricity. In this nucleus, cells essentially differentiate into astrocytes and microglia. Moreover, the kinetics of disappearance of the nystagmus are very fast ( 8 days in the UVN cat model) and occur before the establishment of the processes leading to the neurogenesis (30 days), indicating that these two processes are independent. Measurements of the vestibulo oculomotor reflex (VOR) after neurogenesis blockade might confirm the lack of a role for neurogenesis in the VOR recovery. What are the possible contributions of neurogenesis to static and dynamic compensation? Compensation for the static deficits results from the 
restoration of balanced electrical activity between the VNCs. This finding has been confirmed electrophysiologically in the alert guinea pig (Ris et al., 1995) and cat (Zennou-Azogui et al., 1993). In addition to a rebalanced activity in the VNCs, compensation for dynamic signs requires a more global reorganization of the central nervous system (reviewed in Curthoys, 2000; Dieringer, 1995; Vidal et al., 1998). The neurogenesis phenomenon we highlight is involved in these two aspects. As shown in our previous study, neurogenesis occurring secondary to unilateral vestibular neurectomy contributes to the restoration of static and dynamic postural deficits (dynamic equilibration function), while it does not interfere with the disappearance of horizontal vestibular nystagmus (Dutheil et al., 2009). Neurogenesis does not appear to be involved in the very early mechanisms of static vestibular compensation, because its time course does not match the recovery of vestibular symptoms, such as nystagmus. Rather, we have postulated that neurogenesis contributes to mid- and long-term compensation, since it appears at 30 days after UVN (Tighilet et al., 2007). This phenomenon probably occurs both through structural reconstruction of vestibular connectivity, and functional adaptations involving the modulation of molecular effectors (such as KCC2 channels), which contributes to maintaining the homeostatic excitability necessary for functional recovery (Dutheil et al., 2016).

\section{The deafferented vestibular nuclei: a permissive environment for adult reactive neurogenesis}

The cellular and molecular mechanisms that support injury-induced endogenous neurogenesis are not yet fully understood. However, some environmental conditions have been deciphered. In the deafferented $\mathrm{VN}$, reactive neurogenesis relies on at least three specific conditions (Fig. 5). First, it depends on the level of excitability of the deafferented vestibular environment. We recently demonstrated a remodeling of excitability markers, such as the cation-chloride cotransporter $\mathrm{KCC} 2$ and $\mathrm{GABA}_{\mathrm{A}}$ receptors, during the first three days after UVN (Dutheil et al., 2016). This remodeling favors a depolarizing action of GABA, a neurotransmitter that usually inhibits excitability (Boulenguez et al., 2010, Ben-Ari et al., 2012). The pharmacological modulation of $\mathrm{GABA}_{\mathrm{A}}$ receptors during the post-UVN period significantly alters vestibular reactive neurogenesis and impairs functional restoration (Dutheil et al., 2013). UVN also induces both ipsi- and contralateral upregulation of the apamin-sensitive calciumactivated small conductance $\mathrm{K}^{+}(\mathrm{SK})$ channels, within the first days following the insult (Tighilet et al., 2018). The administration of apamin (SK channel-selective antagonist) during the acute phase of the vestibular syndrome significantly reduces both the postural/locomotor 
and vestibulo-ocular deficits induced by the UVN. These changes are manifested as decreases in both the spontaneous nystagmus and the static and dynamic balance unsteadiness. Thus, strategies that regulate SK channel expression may be part of the changes in excitability that support the vestibular compensation process.

The second condition involves BDNF. The number of immunoreactive neurons to BDNF and TrkB (BDNF receptor) transiently increases in the deafferented VN concomitantly with the cell proliferation peak (Lacour and Tighilet 2010). Blocking BDNF-TrkB signaling significantly reduces neurogenesis and prevents postural locomotor recovery in animals with vestibular injuries. Conversely, a continuous infusion of BDNF from the first day after UVN increases the rates of cell proliferation, survival, and differentiation. Under these conditions, the animals fully restore their balance and posture earlier (Dutheil et al., 2016).

The third essential condition for reactive vestibular neurogenesis is the presence of inflammatory factors in the deafferented VN environment. As soon as UVN is induced, strong astrocytic, microglial and inflammatory reactions favor neurogenesis (Dutheil et al., 2009, 2016, Liberge et al., 2010). A three-day treatment with an anti-inflammatory drug (solumedrol) in UVN animals reduces the cell proliferation observed in the deafferented VN (unpublished data). The synthesis of histamine, which has also been reported to function as a proinflammatory factor that activates microglia (Rocha et al., 2016), is substantially increased after UVN in the posterior hypothalamus and is released in the VN (Tighilet et al., 2006). As histamine promotes hippocampal (Guilloux et al., 2017) and subventricular neurogenesis (Eiriz et al., 2014), it could be an essential factor of reactive neurogenesis in the deafferented VN. Moreover, prohistaminergic drugs, which are used to treat vertigo, favor vestibular compensation (Tighilet et al., 2007). Given that inflammation regulates adult neurogenesis (Whitney et al., 2009), the inflammatory phenomenon expressed acutely in the deafferented VN may facilitate the expression of the observed reactive neurogenesis. Similarly, glia have been shown to modulate neuronal network excitability via different processes, such as $\mathrm{K}^{+}$ clearance (Bellot-Saez et al., 2017) or BDNF signaling (Ferrini and De Koninck, 2013). Glial cells are also considered central components of all neurogenic niches in the embryonic and adult central nervous systems (Falk and Götz, 2017). Neuronal excitability is known to be a key factor for both postnatal neurogenesis and gliogenesis (Káradóttir and Kuo, 2018). Both the concomitance and the interdependence of these different neuroplastic mechanisms indicate that they work in concert to rebalance the level of excitability between the intact and the deafferented VN. This electrophysiological homeostasis is a prerequisite for the induction of reactive vestibular neurogenesis and the subsequent functional recovery. 


\section{Critical period and development recapitulation of developmental processes}

Notably, all the phenomena described above occur during the 3-day window after UVN. AraC infusion during this acute phase blocks neurogenesis and decreases the number of GFAPimmunoreactive cells and GABAergic neurons in the VN of neurectomized cats (Dutheil et al. 2009). At the behavioral level, the time course of postural locomotor function recovery is drastically delayed. In contrast, the infusion of AraC beginning 3 weeks after UVN had no influence on either the time course of behavioral recovery or on the different steps of neurogenesis. We conclude that the first week after UVN represents a likely critical period in which important neuroplastic mechanisms, including neurogenesis, take place to promote vestibular functional recovery. In support of this hypothesis, sensorimotor restriction (SMR) applied during the first week after UVN to both adult cats and monkeys prevents postural recovery, while later application of SMR does not impair the functional recovery time course (Lacour et al., 1976; Xerri and Lacour, 1980). The re-emergence of such a critical period during the postlesional reparative time is reminiscent of some stages of development, during which both neurogenesis and the peak expression of depolarizing GABA and neurotrophins are together solicited. Therefore, the injured adult vestibule may use the same developmental recipes for its reconstruction and functionality.

\section{Adult reactive neurogenesis and sensory systems}

Reactive adult cortical neurogenesis has previously been observed in patients with amyotrophic lateral sclerosis (Chi et al., 2006), epilepsy (Scott et al., 1998; Jessberger and Parent, 2008), and multiple sclerosis (Danilov et al., 2006), after focal apoptosis (Magavi et al., 2000) as well as in rodent models of ischemia (Parent, 2002; Thored et al., 2006; Ling et

al., 2009). However, few investigations have addressed the question of whether adult reactive neurogenesis occurs in sensory systems following damages to the sensory nerve. Vessal and Darian-Smith (2010) presented the first evidence that adult neurogenesis occurs in the nonhuman primate primary somatosensory and motor cortex in direct response to a spinal dorsal root injury. Importantly, they provided strong evidence that new neurons formed within the reorganized but uninjured cortex in response to a cervical deafferentation, as many synapses at the site of injury and significant gliosis associated with the injury were observed. Neither the environmental conditions that support injury-induced endogenous neurogenesis, nor the functional relevance of this phenomenon in the subsequent recovery of hand function have been established. 
Adult neurogenesis is also involved in peripheral sensory systems, during the regeneration of photoreceptors, olfactory sensory cells and vestibular hair cells (Farbman 1997 for review). However, few studies have reported that damage to a peripheral sensory system induces cell proliferation that may be related to central neurogenesis. Bilateral surgical lesions of the cochlea result in cell proliferation in the cochlear nucleus of the brainstem in adult rats (Zheng et al., 2011). A similar plastic phenomenon was subsequently observed after acoustic trauma in adult rats (Zheng et al., 2015). The functional significance of this process has not been determined. It can be assumed, that the new cells undergo apoptosis or remain nonfunctional. Another possibility is that some of the new neurons become functional by integrating into the local neural circuitry and contributing to adaptive or maladaptive plasticity. In a more recent study, we confirmed the existence of reactive neurogenesis in the cochlear nuclei of the brain stem, subsequent to vestibule cochlear nerve section. Some of the mechanisms that have been previously reported in the deafferented vestibular nuclei, such as the KCC2 downregulation (suggesting that GABA may become excitatory), were also observed. The functionality of the newborn neurons remains an open question. One possibility is that they support a maladaptive plasticity such as tinnitus or hyperacusis (Tighilet et al. 2016).

\section{Clinical relevance}

Over the two last decades, the use of surgical approaches to treat Ménière's disease (including vestibular neurectomy, labyrinthectomy and ablation of the endolymphatic sac) has significantly decreased. Simultaneously, the intratympanic administration of gentamicin therapy has increased to become the most frequently used invasive treatment for Ménière's disease (Silverstein et al. 2003). However, one of the main advantages of the neurectomy is that it preserved the hearing of more than $98 \%$ of patients (Silverstein et al. 1989; Pareschi et al. 2002; Schlegel et al. 2012), whereas labyrinthectomy systematically sacrifices hearing (Diaz et al. 2017). Unfortunately, current clinical imaging technics do not allow for checking the presence of newborn neurons in deafferented vestibular nuclei in response to curative vestibular neurectomy. Given the phylogenetic proximity, neurogenesis likely occurs in the brain stem of patients after vestibular neurectomy. We can question the impact of this mechanism in the disappearance of the syndrome and the implementation of the vestibular compensation. Different animal models of vestibular lesions have been developed (Lacour et al., 2009, Dutheil et al. 2011) that reproduce either reversible blockage of peripheral inputs (inner ear injection of tetrodotoxin), permanent loss of peripheral sensors only (unilateral 
labyrinthectomy -UL- model), or complete removal of both peripheral sensors and Scarpa's ganglion (UVN model) to compare the compensation capacities according to the type of peripheral impairment and the neuroplasticity mechanisms involved. In the two first cases, the mechanisms that occur in the brainstem vestibular nuclei include the modulation of neurotransmitter, neurohormone, and/or neurotrophic factor synthesis. Conversely, in the case of UVN, in which the peripheral inputs are completely lost, the aforementioned plasticity mechanisms are observed to a greater extent and structural changes, such as neurogenesis, are established within the vestibular nuclei. The time courses and mechanisms of recovery depend on the type of vestibular deafferentation. In support of this hypothesis, patients who undergo neurectomy have been reported to experience a significant correction of their functional deficits within a few months after surgical intervention (Redon et al., 2011). We presume that this effect may rely on neurogenesis. This type of emergency rescue may occur to replace the loss of secondary vestibular neurons in the brainstem during aging (Lopez et al., 1997; Zalewski, 2015). This question also extends to the age-related loss of primary vestibular neurons and hair cells (Rosenhall, 1973).

\section{Future directions}

The discovery of the involvement of adult reactive neurogenesis in the vestibular compensation process raises both basic and translational questions. In terms of priority, more thorough investigations of the origins and fate of the newborn neurons in the VN are needed. Mouse strains in which stem cells are specifically labeled may allow researchers to define the types and location of neural precursors, as well as the characteristics of integration (arborization and synaptic contacts) of the new neurons, in preexisting networks. Molecular electrophysiological approaches for brainstem slices should be developed to confirm the electrophysiological signatures of the different cell types and their roles in restoring the excitability of the deafferented vestibular environment. Pharmacological modulation of each of the cell types (astrocytes, microglia, and neurons) should improve our understanding of their respective contributions to the overall functional recovery process.

Confirming the existence of such a phenomenon in humans is of course a prerequisite for any therapeutic intervention aimed at accelerating and optimizing vestibular compensation for a faster and better recovery of gait and balance. However, we must accept that established clinical protocols for functional imaging that are suitable to depict neurogenesis to the extent expected from animal models are currently unavailable. The observation of a critical time window of intense postlesional plasticity delineates a putative therapeutic window in which 
drug actions should be most effective in influencing local plasticity and subsequent functional restoration. Unlike the auditory system, the damaged adult peripheral vestibular system is able to generate new hair cells, albeit in limited numbers (Li et al., 2003). The adult central vestibular system also initiates functional neurogenesis upon traumatic injury. Based on these findings, cells in adult vestibular tissues retain regenerative and proliferative capacities. The identification of the molecular effectors that control these properties might be relevant to regenerative medicine based on stem-cell-mediated replacement of damaged or lost inner ear hair cells and neurons, as well as the development of cochlear and vestibular implants. Indeed, based on current advances in these respective fields (Czalkowski et al. 2018; Lenarz 2018), the next true challenge will consist of integrating and reconnecting the newly generated cells and devices into preexisting networks.

\section{Conclusion}

This review describes the phenomenon of adult reactive neurogenesis that occurs in the vestibular nuclei upon the loss of the inputs arising from peripheral vestibular sensors. This phenomenon originates in a deafferented environment in which different biochemical and electrophysiological processes are profoundly shaken. The concomitance and interdependence of these different processes indicates the presence of coordinated mechanisms that contribute to the establishment of a new functional neural network. The setting of this new network authorizes the use of substitutive sensory information to replace the loss of the original vestibular sensory inputs. Although this process has not yet been confirmed in humans, it may be a key mechanism in the process of vestibular compensation, which drives the spontaneous recovery of gait and balance. Future insights related to our understanding of the origin and fate of adult reactive vestibular neurogenesis should provide therapeutic solutions to stimulate this process and optimize the restoration of gait and balance. Additionally, better knowledge of the characteristics of this specific phenomenon may provide a better understanding of the global rules that govern adult neurogenesis. 


\section{Legends}

Fig.1: Schematics of sensory heteromodal inputs into vestibular nuclei and their functional consequences in normal (A) and unilateral vestibular loss conditions (B).

Fig.2: Kinetic of reactive neuroplasticity mechanisms in the deafferented vestibular nuclei. This figure illustrates the temporal correlation between static and dynamic vestibular syndrome, reactive plasticity mechanisms taking place in the vestibular nuclei following unilateral neurectomy, and electrophysiological adjustment in the $\mathrm{VN}$, that support vestibular compensation. Adapted from Beraneck and Idoux, 2012.

Fig. 3: Histological evidence of adult cell proliferation in the deafferented vestibular nuclei of the cat and its impact on the postural and locomotor functions. A-B: Proliferating, BrdU-immunoreactive cells (arrow) in deafferented medial VN in cats infused with a control saline solution $(\mathrm{NaCl}, \mathrm{A})$ or antimitotic $(\mathrm{AraC}, \mathrm{B})$ in the fourth ventricle 30 days after UVN. Vestibular nerve sections exhibited a substantial increase in the number of BrdU-immunoreactive cells in the deafferented medial $\mathrm{VN}$ following the $\mathrm{NaCl}$ infusion, whereas no BrdU-immunoreactive cells were observed in the medial VN after an AraC infusion (scale bar: $50 \mu \mathrm{m}$ ). C: Evolution of the mean postoperative support surface, as delimited by the four legs of the cat standing erect without walking (in square centimeters). Data recorded after vestibular deafferentation were related to individual references and normalized to the preoperative values referred to unity (one being close to $50 \mathrm{~cm}^{2}$ ). SEMs of the means are shown as vertical lines. Note the longer recovery time when AraC was infused immediately after UVN (86 days instead of 50 days). D: The maximal performance (Max P) in the dynamic equilibrium task is defined as the highest beam rotation speed that did not lead to a fall on four consecutive crossings. This value is presented as a percentage of the preoperative maximal performance over postoperative time in days (on the abscissae). SEMs are shown as vertical lines. Full recovery takes much longer when AraC is infused immediately after UVN (146 days instead of 46 days). Adapted from Dutheil et al., 2009.

Fig. 4: Newly generated cells differentiate into neurons, astrocytes and microglial cells. Confocal images of newly generated cells immunolabeled with both BrdU (red) and specific markers of cell differentiation (green) reveal three cell lineages: neurons (NeuN: neuronal nuclei marker), astrocytes (GFAP: glial fibrillary acidic protein), and microglial cells (IBA1: ionized calcium binding adapter molecule 1). Among the neural cell populations, a proportion 
was immunoreactive to GAD 67 (glutamate decarboxylase: GABA-synthesizing enzyme) indicating their GABAergic phenotype. Representative images of differentiating cells were obtained from deafferented medial vestibular nuclei 30 days after UVN. Taken from Dutheil et al., 2013.

Fig. 5: The deafferented vestibular nuclei: a permissive environment for adult reactive neurogenesis. In the adult brain, under physiological conditions or on the intact side of the $\mathrm{VN}$ (right panel), the presence of KCC2 in the neuronal membrane leads to a low inner $\mathrm{Cl}^{-}$ concentration. When GABA activates $\mathrm{GABA}_{\mathrm{A}}$ receptors, it triggers an influx of $\mathrm{Cl}^{-}$, which hyperpolarizes the membrane. After UVN (left panel), microglia and astrocytes are strongly activated in the deafferented VN. We hypothesize that microglia and nerve terminals release BDNF, which in turn activates TrkB receptors and downregulates KCC2 expression. Downregulation of $\mathrm{KCC} 2$ decreases chloride extrusion from the cell. $\mathrm{Cl}^{-}$ions then accumulate in the cell and the transmembrane chloride gradient collapses. Because the anion flux is inverted, when $\mathrm{GABA}$ opens $\mathrm{GABA}_{\mathrm{A}}$ receptors, $\mathrm{Cl}^{-}$ions leaving the cell depolarize the cell membrane and subsequently increase the cell excitability. Interestingly, at the same time point ( 3 days after $\mathrm{UVN}$ ), a peak of $\mathrm{BrdU}^{+}$cells is observed in the deafferented $\mathrm{VN}$ and correlates with the peak in BDNF expression. Thus, BDNF, which is released by both neurons and glia, also potentially modulates cell proliferation, survival and excitability. All these molecular mechanisms have the common goal of restoring the excitability of the deafferented $\mathrm{VN}$, which is crucial for the different steps of neurogenesis (proliferation, survival, differentiation and integration into functional neural networks) and subsequent functional recovery (Dutheil et al., 2013). Adapted from Dutheil et al., 2016. 


\section{Bibliography}

Angelaki DE, Cullen KE. Vestibular system: the many facets of a multimodal sense. Annu Rev Neurosci (2008) 31: 125-150.

Balaban CD. Vestibular autonomic regulation (including motion sickness and the mechanism of vomiting). Curr Opin Neurol (1999) 12(1): 29-33.

Bellot-Saez A, Kékesi O, Morley JW, Buskila Y. Astrocytic modulation of neuronal excitability through $\mathrm{K}^{+}$spatial buffering. Neurosci Biobehav Rev (2017) 77: 87-97. doi: 10.1016/j.neubiorev.2017.03.002.

Ben-Ari Y, Khalilov I, Kahle KT, Cherubini E. The GABA excitatory/inhibitory shift in brain maturation and neurological disorders. Neuroscientist (2012) 18(5): 467-86.

Beraneck M, Idoux, E. Reconsidering the role of neuronal intrinsic properties and neuromodulation in vestibular homeostasis. Front. Neurol. (2012) 3(25). 10.3389/fneur.2012.00025.

Boulenguez P, Liabeuf S, Bos R, Bras H, Jean-Xavier C, Brocard C, Stil A, Darbon P, Cattaert D, Delpire E, Marsala M, Vinay L. Down-regulation of the potassium-chloride cotransporter KCC2 contributes to spasticity after spinal cord injury. Nat Med (2010) 16(3): 302-7. doi: 10.1038/nm.2107. Epub 2010 Feb 28.

Brichta AM, Goldberg JM. Responses to efferent activation and excitatory response-intensity relations of turtle posterior-crista afferents. J Neurophysiol (2000) 83: 1224-1242.

Chi L, Ke Y, Luo C, Li B, Gozal D, Kalyanaraman B, Liu R. Motor neuron degeneration promotes neural progenitor cell proliferation, migration, and neurogenesis in the spinal cords of amyotrophic lateral sclerosis mice. Stem Cells (2006) 24:34-43.

Curthoys IS. Vestibular compensation and substitution. Curr Opin Neurol. (2000) (1):27-30. Review.

Danilov AI, Covacu R, Moe MC, Langmoen IA, Johansson CB, Olsson T, Brundin L. Neurogenesis in the adult spinal cord in an experimental model of multiple sclerosis. Eur J Neurosci (2006) 23:394-400.

Darlington CL, Dutia MB, Smith PF. The contribution of the intrinsic excitability of vestibular nucleus neurons to recovery from vestibular damage. Eur J Neurosci (2002) 15(11): 1719-27.

Darlington CL, Smith PF. Molecular mechanisms of recovery from vestibular damage in mammals: recent advances. Prog Neurobiol (2000) $62: 313-25$. 
Diaz RC, LaRouere MJ, Bojrad DJ, Zappia JJ, Sargent EW, Shaia WT. Quality of life assessment of Ménière's disease patients alter surgical labyrinthectomy. Otol Neurotol (2017) 28(1):74-86.

Dieringer N. Vestibular compensation: neural plasticity and its relations to functional recovery after labyrinthine lesions in frogs and other vertebrates. Prog Neurobiol (1995) 46 (2-3): 97-129. Review. Doi : 10.1016/0301-0082(95)80009-W.

Dutheil S, Lacour M, Tighilet B. Neurogenic potential within the vestibular nuclei and behavioural time course recovery in the adult cat are governed by the nature of the vestibular damage. PLoS One (2011) 6(8): e22262.

Dutheil S, Brezun JM, Leonard J, Lacour M, Tighilet B. Neurogenesis and astrogenesis contribution to recovery of vestibular functions in the adult cat following unilateral vestibular neurectomy: cellular and behavioural evidence. Neuroscience (2009) 164: 1444-56.

Dutheil S, Escoffier G, Gharbi A, Watabe I, Tighilet B. GABA(A) receptor agonist and antagonist alter vestibular compensation and different steps of reactive neurogenesis in deafferented vestibular nuclei of adult cats. J Neurosci (2013) 33(39): 15555-66.

Dutheil S, Watabe I, Sadlaoud K, Tonetto A, Tighilet B. BDNF signalling promotes vestibular compensation by increasing neurogenesis and remodelling the expression of potassium-chloride cotransporter KCC2 and GABAa receptor in the vestibular nuclei. $\mathbf{J}$ Neurosci (2016) 36(23): 6199-6212.

Eiriz MF, Valero J, Malva JO, Bernardino L. New insights into the role of histamine in subventricular zone-olfactory bulb neurogenesis. Front Neurosci (2014) 8:142. doi: 10.3389/fnins.2014.00142. eCollection 2014.

Falk S, Götz M. Glial control of neurogenesis. Curr Opin Neurobiol (2017) 47:188-195. doi: 10.1016/j.conb.2017.10.025.

Farbman AI. Injury-stimulated neurogenesis in sensory systems. Adv Neurol (1997) 72:157161.

Ferensztajn-Rochowiak E, Kucharska-Mazur J, Tarnowski M, Samochowiec J, Ratajczak MZ, Rybakowski JK. Stem cells, pluripotency and glial cell markers in peripheral blood of bipolar patients on long-term lithium treatment. Prog Neuropsychopharmacol Biol Psy (2018) 80:28-33. doi: 10.1016/j.pnpbp.2017.06.013.

Ferrini F, De Koninck Y. Microglia control neuronal network excitability via BDNF signalling. Neural Plast (2013) 429815. doi: 10.1155/2013/429815.

Gage FH. Neurogenesis in the adult brain. J Neurosci (2002) 22(3): 612-3. 
Guilloux JP, Samuels BA, Mendez-David I, Hu A, Levinstein M, Faye C, Mekiri M, Mocaer E, Gardier AM, Hen R, Sors A, David DJ. S 38093, a histamine antagonist/inverse agonist, promotes hippocampal neurogenesis and improves context discrimination task in aged mice. Sci Rep (2017) 7:42946. doi: 10.1038/srep42946.

Gustave Dit Duflo S, Gestreau C, Tighilet B, Lacour M. Fos expression in the cat brainstem after unilateral vestibular neurectomy. Brain Res. (1999) 824(1):1-17.

Jessberger, S.; Parent, JM. Epilepsy and adult neurogenesis. In: Gage, FH.; Kempermann, G.; Song, H., editors. Adult Neurogenesis. New York: Cold Spring Harbor Laboratory Press; 2008. p. 535-548.

Jones SM, Jones TA, Mills KN, Gaines GC. Anatomical and physiological considerations in vestibular dysfunction and compensation. Semin Hear (2009) 30(4): 231-241.

Káradóttir RT, Kuo CT. Neuronal Activity-Dependent Control of Postnatal Neurogenesis and Gliogenesis. Annu Rev Neurosci (2018) Apr 4. doi: 10.1146/annurev-neuro-072116031054.

Lacour M, Bernard-Demanze L. Interaction between Vestibular Compensation Mechanisms and Vestibular Rehabilitation Therapy: 10 Recommendations for Optimal Functional Recovery. Front Neurol. (2015) 5:285. doi: 10.3389/fneur.2014.00285. eCollection 2014. Review.

Lacour M, Dutheil S, Tighilet B, Lopez C, Borel L. Tell me your vestibular deficit, and I'll tell you how you'll compensate. Ann N Y Acad Sci. (2009) 1164:268-78. doi: 10.1111/j.1749-6632.2008.03731.x.

Lacour M, Tighilet B. Plastic events in the vestibular nuclei during vestibular compensation: the brain orchestration of a deafferentation code. Rest Neurol Neurosci (2010) 27: 1-17.

Lacour M, Roll JP, Appaix M. Modifications and development of spinal reflexes in the alert baboon (Papio papio) following an unilateral vestibular neurotomy. Brain Res (1976) 113(2): 255-269.

Lacour M, Helmchen C, Vidal PP. Vestibular compensation: the neuro-otologist's best friend. J Neurol (2016) 263 Suppl 1: S54-64. doi: 10.1007/s00415-015-7903-4.

Lenarz T. Cochlear implant - state of the art. GMS Curr Top Otorhinolaryngol Head Neck Surg. (2018) Feb 19;16: Doc04. doi: 10.3205/cto000143.

Li H, Dokas LA, Godfrey DA, Rubin AM. Remodeling of synaptic connections in the deafferented vestibular nuclear complex. J Vestib Res (2002) 12(4): 167-83. 
Liberge M, Manrique C, Bernard-Demanze L, Lacour M. Changes in TNFa, NFkB and MnSOD protein in the vestibular nuclei after unilateral vestibular deafferentation. $\mathrm{J}$ Neuroinflam (2010) 7: 91.

Ling L, Zeng J, Pei Z, Cheung RTF, Hou Q, Xing S, Zhang S. Neurogenesis and angiogenesis within the ipsilateral thalamus with secondary damage after focal cortical infarction in hypertensive rats. J Cereb Blood Flow Metab (2009) 29:1538-1546.

Lopez C. The vestibular system: balancing more than just the body. Curr Opin Neurol (2016) 29(1): 74-83. doi: 10.1097/WCO.0000000000000286.

Lopez I, Honrubia V, Baloh R W. Aging and the human vestibular nucleus. J Vestib Res (1997) 7(1): 77-85.

Magavi SS, Leavitt BR, Macklis JD. Induction of neurogenesis in the neocortex of adult mice. Nature (2000) 405:951-955.

Parent JM. The role of seizure-induced neurogenesis in epilepto-genesis and brain repair. Epilepsy Res (2002) 50:179-189.

Pareschi R, Destito D, Falco Raucci A, Righini S, Colombo S. Posterior fossa vestibular neurotomy as primary surgical treatment of Menière's disease: a reevaluation. J Laryngol Otol (2002) 116(8):593-6.

Raymond J, Ez-Zaher L, Demêmes D, Lacour M. Quantification of synaptic density changes in the medial vestibular nucleus of the cat following vestibular neurectomy. Restor Neurol Neurosci (1991) 3(4): 197-203. doi: 10.3233/RNN-1991-3404.

Redon C, Lopez C, Bernard-Demanze L, Dumitrescu M, Magnan J, Lacour M, Borel L. Betahistine treatment improves the recovery of static symptoms in patients with unilateral vestibular loss. J Clin Pharmacol (2011) 51(4): 538-48. doi: $10.1177 / 0091270010369241$.

Ris L, de Waele C, Serafin M, et al. Neuronal activity in the ipsilateral vestibular nucleus following unilateral labyrinthectomy in the alert guinea pig. J Neurophysiol (1995) ; 74 : 2087-99.

Rocha SM, Saraiva T, Cristóvão AC, Ferreira R, Santos T, Esteves M, Saraiva C, Je G, Cortes L, Valero J, Alves G, Klibanov A, Kim YS, Bernardino L. Histamine induces microglia activation and dopaminergic neuronal toxicity via $\mathrm{H} 1$ receptor activation. $\mathrm{J}$ Neuroinflammation (2016) 13(1): 137. doi: 10.1186/s12974-016-0600-0.

Rosenhall U. Degenerative patterns in the aging human vestibular neuro-epithelia. Acta Otolaryngol (1973) 76(2): 208-220. 
Schlegel M, Vibert D, Ott SR, Häusler R, Caversaccio MD. Functional results and quality of life after retrosigmoid vestibular neurectomy in patients with Ménière's disease. Otol. Neurotol. (2012) 33:1380-1385.

Scott B, Wang S, Burnham W, De Boni U, Wojtowicz J. Kindling-induced neurogenesis in the dentate gyrus of the rat. Neurosci Lett (1998) 248:73-76.

Silverstein H, Lewis WB, Jackson LE, Rosenberg SI, Thompson JH, Hoffmann KK. Changing trends in the surgical treatment of Ménière's disease: results of a 10-year survey. Ear Nose Throat J. (2003) 82(3):185-7, 191-4.

Silverstein H, Norrell H, Smouha E, Jones R. Combined retrolab-retrosigmoid vestibular neurectomy. An evolution in approach. Am. J. Otol. (1989) 10:166-169.

Smith PF, Curthoys IS. Mechanisms of recovery following unilateral labyrinthectomy: a review. Brain Res Brain Res Rev (1989) 14(2): 155-80.

Stellos K, Panagiota V, Sachsenmaier S, Trunk T, Straten G, Leyhe T, Seizer P, Geisler T, Gawaz M, Laske C. Increased circulating progenitor cells in Alzheimer's disease patients with moderate to severe dementia: evidence for vascular repair and tissue regeneration? J Alzheimers Dis (2010) 19(2): 591-600. doi: 10.3233/JAD-2010-1261.

Strupp M, Arbusow V. Acute vestibulopathy. Curr Opin Neurol (2001) 14(1): 11-20.

Tighilet B, Brezun JM, Gustave Dit Duflo S, Gaubert C, Lacour M. New neurons in the vestibular nuclei complex after unilateral vestibular neurectomy in the adult cat. Eur $\mathbf{J}$ Neurosci (2007) 1: 47-58.

Tighilet B, Manrique C, Lacour M. Stress axis plasticity during vestibular compensation in the adult cat. Neuroscience. (2009) 160(4): 716-30. doi: 10.1016/j.neuroscience.2009.02.070.

Tighilet B, Dutheil S, Siponen MI, Noreña AJ. Reactive Neurogenesis and Down-Regulation of the Potassium-Chloride Cotransporter KCC2 in the Cochlear Nuclei after Cochlear Deafferentation. Front Pharmacol (2016) Aug 31;7:281. doi: 10.3389/fphar.2016.00281.

Tighilet B, Leonard J, Mourre C, Chabbert C. Apamin treatment accelerates equilibrium recovery and gaze stabilization in unilateral vestibular neurectomized cats: cellular and behavioral aspects Neuropharmacol (2018) doi: 10.1016/j.neuropharm.2018.10.029.

Tighilet B, Trottier S, Mourre C, Lacour M. Changes in the histaminergic system during vestibular compensation in the cat. J Physiol Lond (2006) 573(3): 723-739.

Thored P, Avidsson A, Cacci E, Ahlenius H, Kallur T, Darsalia V, Ekdahl CT, Kokaia Z, Lindvall O. Persistent production of neurons from adult brain stem cells during recovery after stroke. Stem Cells (2006) 24:739-747. 
Vessal M, Darian-Smith C. Adult neurogenesis occurs in primate sensorimotor cortex following cervical dorsal rhizotomy. J Neurosci. (2010) June 23; 30(25): 8613-8623. doi:10.1523/JNEUROSCI.5272-09.2010.

Vidal PP, de Waele C, Vibert N, Muhlethaler M. Vestibular compensation revisited. Otolaryngol Head Neck Surg (1998) 119:34-42.

Whitney NP, Eidem TM, Peng H, Huang Y, Zheng JC. inflammation mediates varying effects in neurogenesis: relevance to the pathogenesis of brain injury and neurodegenerative disorders. J Neurochem (2009) 108(6): 1343-59. doi: 10.1111/j.1471-4159.2009.05886.

Wilson VJ, Melvill Jones G. Mammalian Vestibular Physiology. (1979) Plenum Press, New York, London.

Xerri C, Lacour M. Compensation deficits in posture and kinetics following unilateral vestibular neurectomy in cats. The role of sensorimotor activity. Acta Otolaryngol (1980) 90(5-6): 414-24.

Zalewski CZ. Aging of the Human Vestibular System Semin Hear (2015) 36(3): 175-196.

Zennou-Azogui Y, Borel L, Lacour M, et al. Recovery of head postural control following unilateral vestibular neurectomy in the cat. Neck muscle activity and neuronal correlates in Deiters' nuclei. Acta Otolaryngol Suppl (1993) 509: 1-19.

Zheng Y, Begum S, Zhang C, Fleming K, Masumura C, Zhang M, Smith PF, Darlington CL. Increased BrdU incorporation reflecting DNA repair, neuronal de-differentiation or possible neurogenesis in the adult cochlear nucleus following bilateral cochlear lesions in the rat. Exp Brain Res (2011) 210:477-487.

Zheng Y, Begum S, Zhang C, Fleming K, Masumura C, Zhang M, Smith P, Darlington C. Increased BrdU incorporation reflecting DNA repair, neuronal de-differentiation or possible neurogenesis in the adult cochlear nucleus following bilateral cochlear lesions in the rat. Exp Brain Res (2011) 210:477-487. doi 10.1007/s00221-010-2491-0 


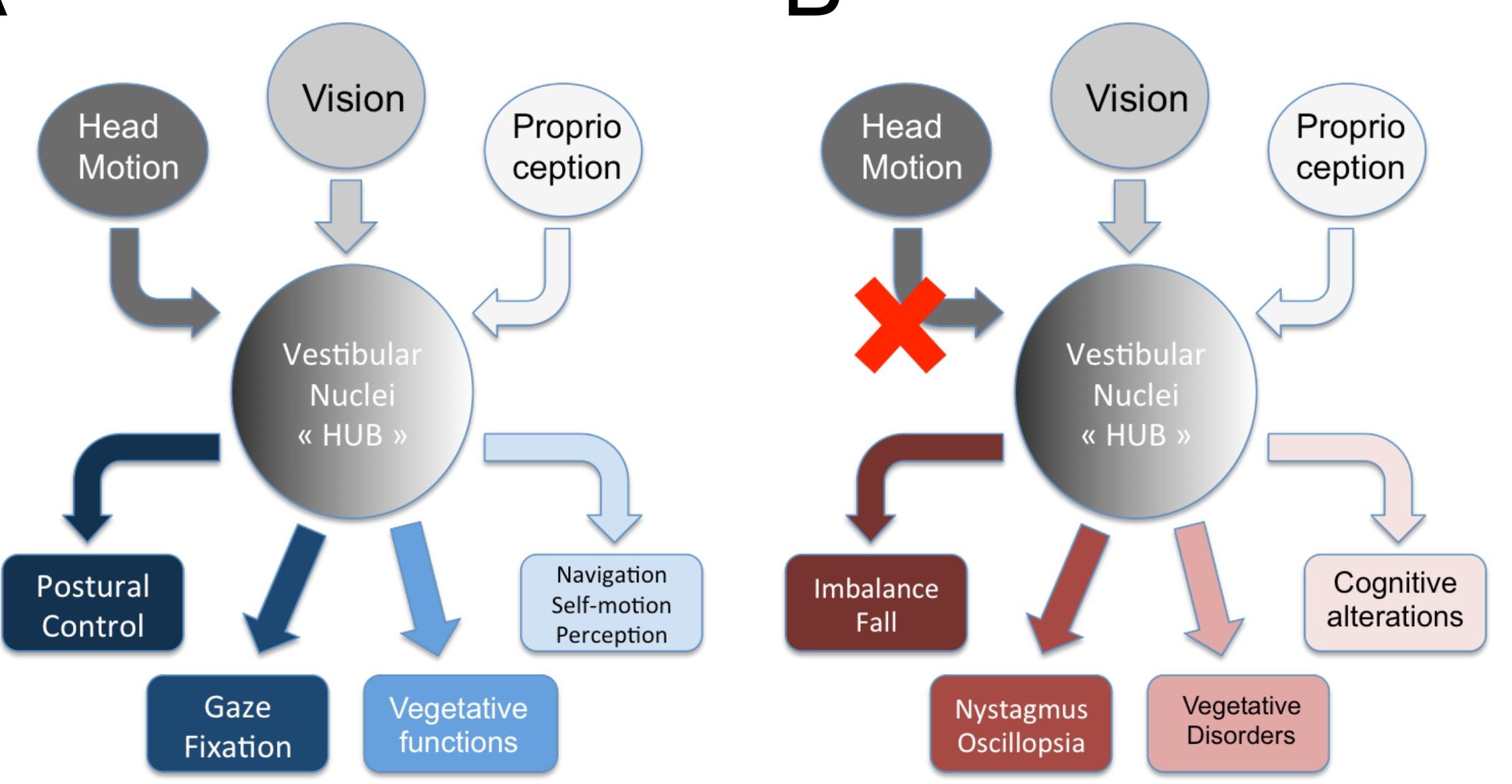




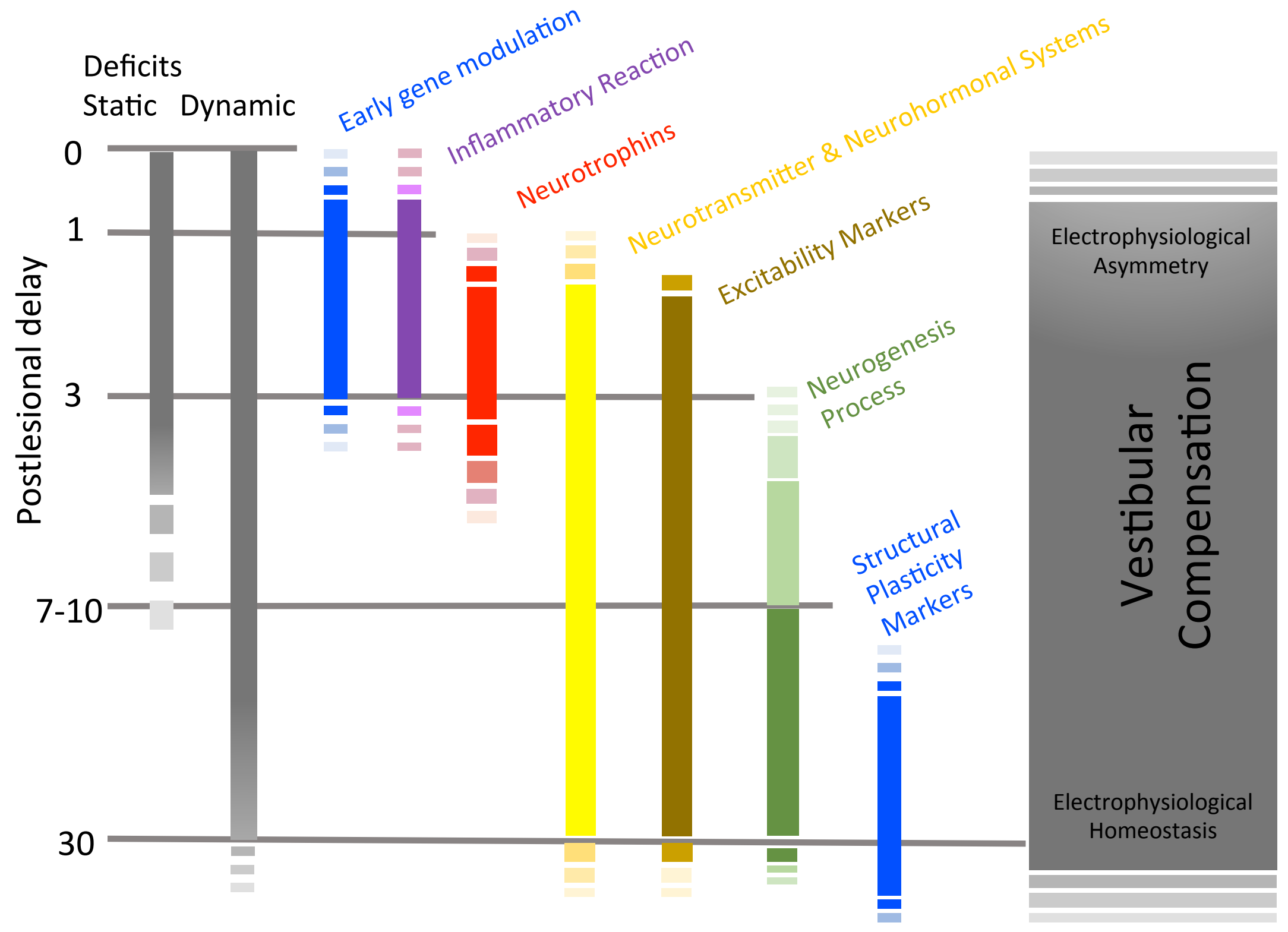



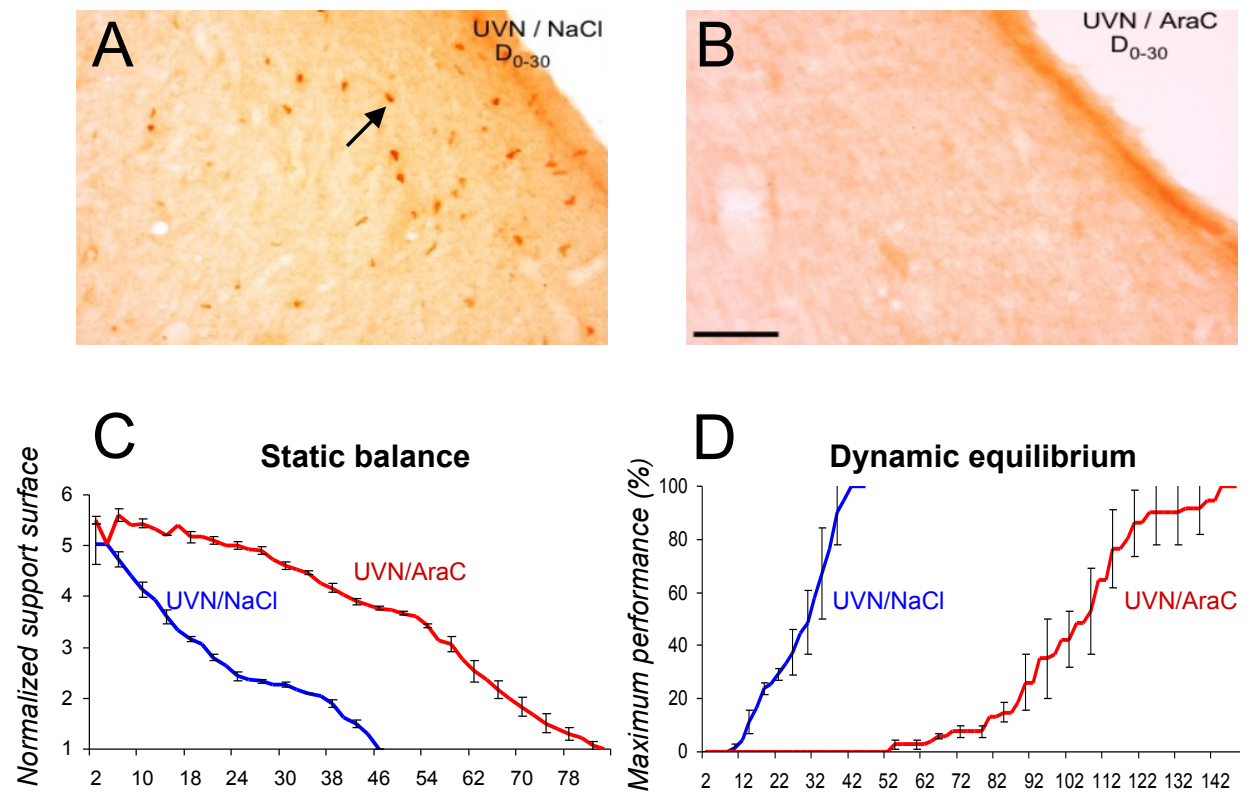

Post-lesionnal time (days) 

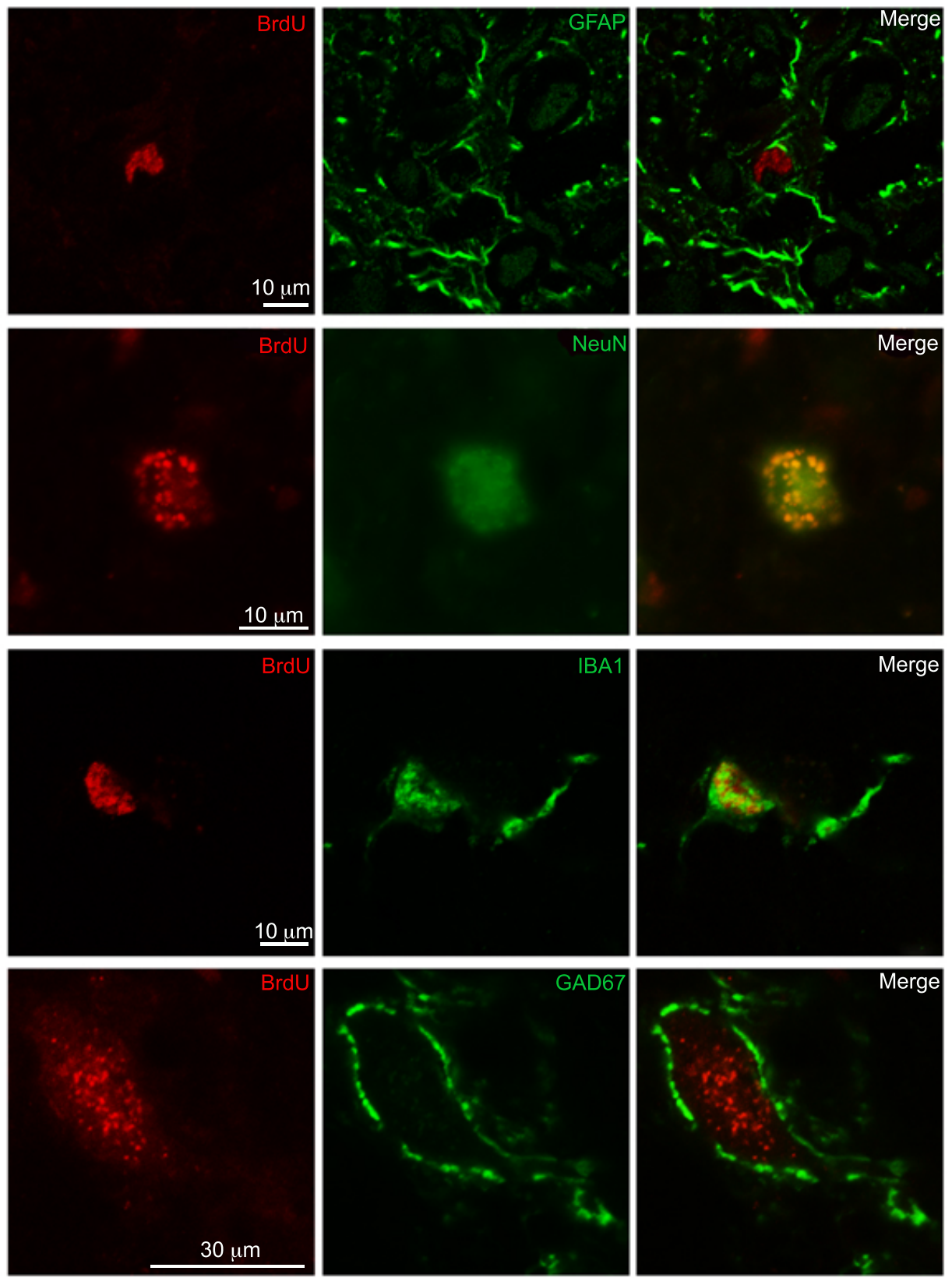


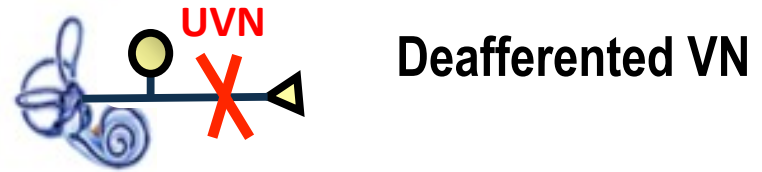

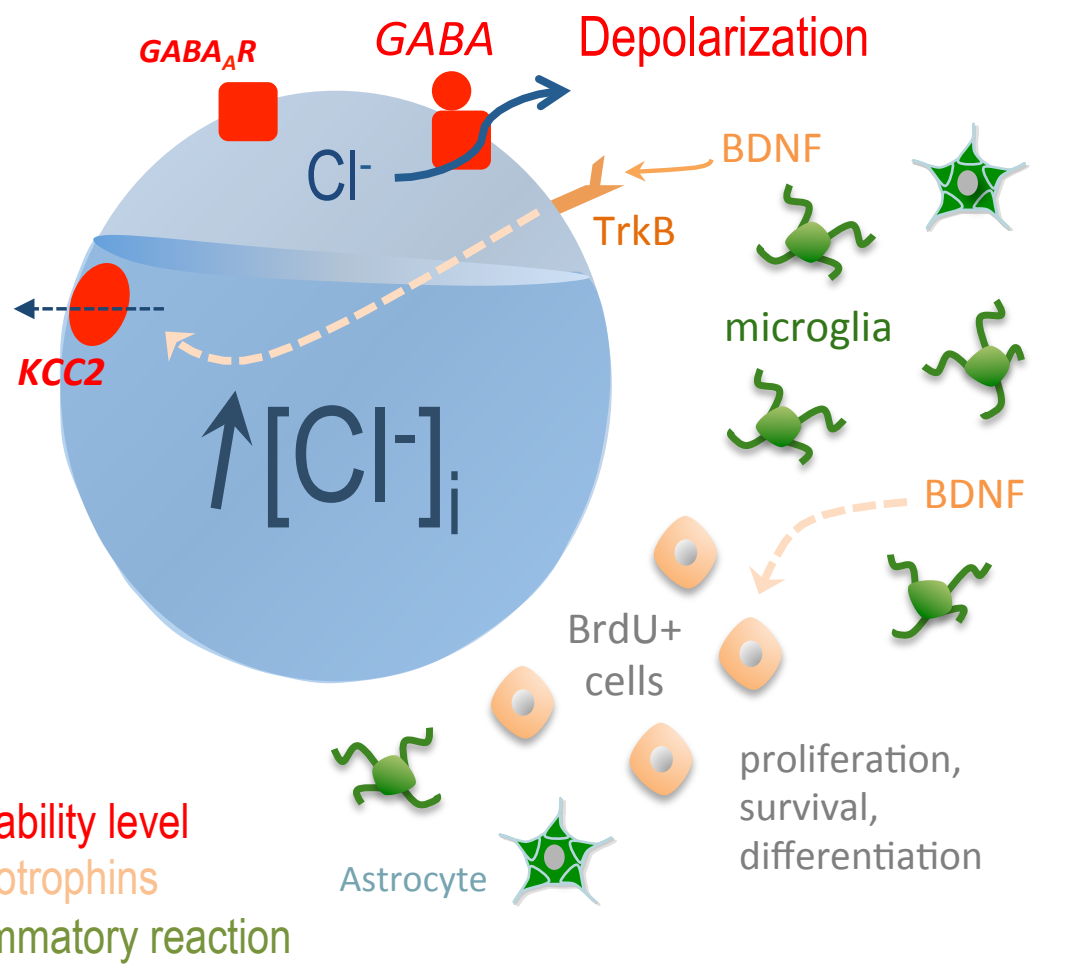

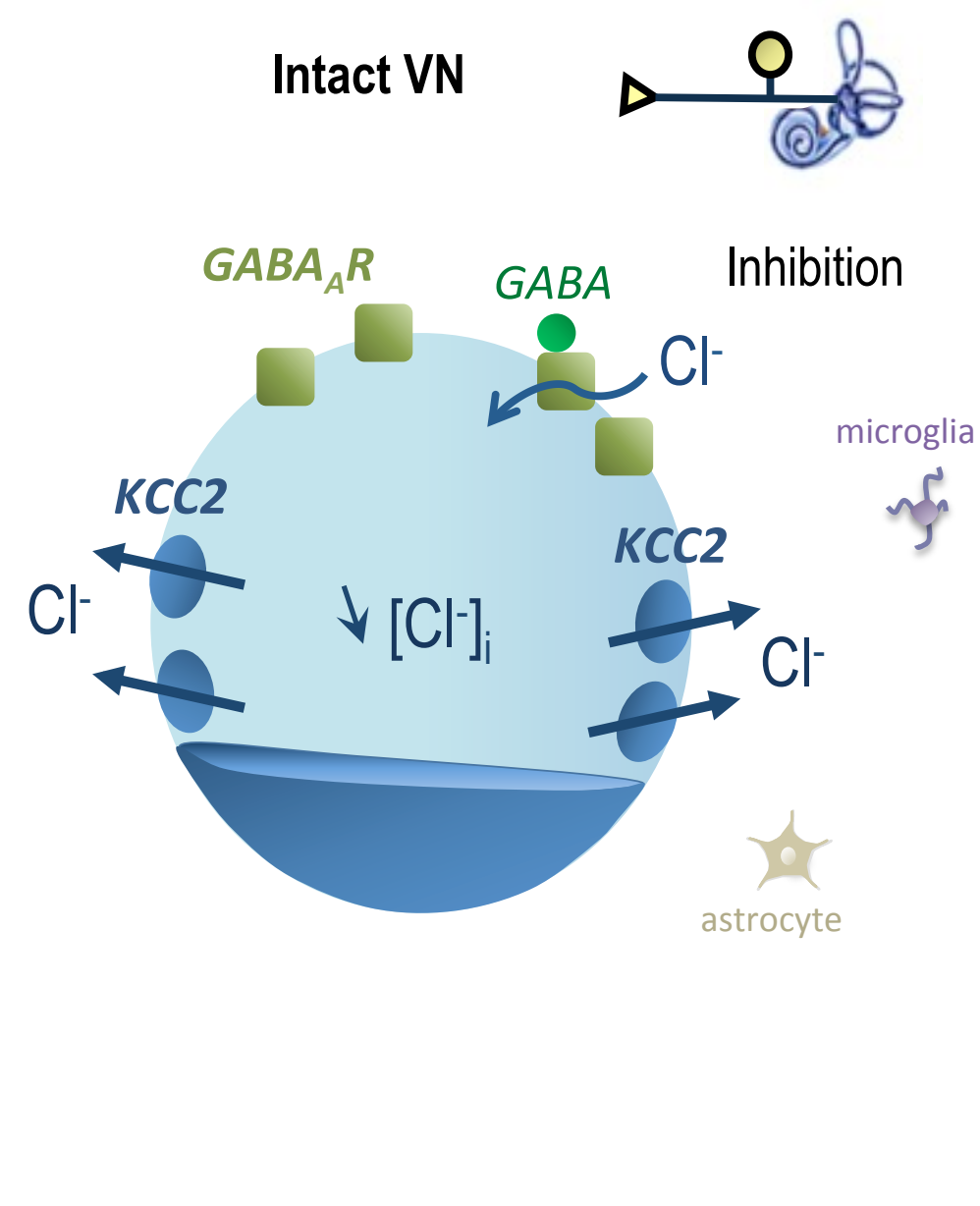

